\title{
RESPUESTA A RODRfGUEZ LARRETA Y ORAYEN
}

EUGENIO BULYGIN

Universidad Nacional de la Plata

Las muy interesantes notas críticas de Juan Rodríguez Larreta y Raúl Orayen merecen sin duda una respuesta más detallada. Pero para no alargar demasiado la discusión, me limitaré a unas pocas observaciones sueltas.

1. Rodríguez Larreta tiene razón en sostener que el argumento de Leibniz es inválido, aun en la forma debilitada en que aparece en el punto $3 \mathrm{de}$ mi artículo. Las perfecciones de Dios sólo garantizan que Dios eligió la mejor alternativa de las que estaban a su disposición, pero no aseguran que el mundo así creado no pudiera ser mejor. Una vez que Dios ha optado por crear hombres libres, la bondad del mundo ya no depende únicamente de él, sino de cómo usan los hombres su libertad.

2. Orayen demuestra en forma concluyente que el problema de la omnisciencia divina es totalmente independiente del problema del conocimiento de los futuros contingentes. Su dilema podría generalizarse aún más:

$\mathrm{O}$ bien (a) el conocimiento de los futuros contingentes es lógicamente posible, o bien

(b) tal conocimiento es lógicamente imposible.

En la primera alternativa, Dios omnisciente conoce los futuros contingentes y entre ellos las acciones libres de los hombres, $y$ hay futuros contingentes, pues si no los hubiera no sería posible conocerlos. Si admitimos la segunda alternativa, Dios no conoce los futuros contingentes, sea porque no los hay (porque todos los hechos son necesarios, esto es, determinados), sea porque su naturaleza es tal que no pueden ser conocidos. En ambos casos la imposibilidad lógica 
de conocerlos no afecta la omnisciencia divina, por las razones que se dan en el artículo. De esta manera resulta innecesario sostener la tesis (ciertamente discutible) de que las proposiciones futuras contingentes carecen de valor de verdad para afirmar la compatibilidad entre la omnisciencia y la libertad.

3. Si bien la omnisciencia resulta en todos los casos compatible con la existencia de acciones libres, esto no significa que los dos cuernos del dilema de Orayen sean equivalentes desde el punto de vista teológico. Los teólogos preferirán, sin duda, la primera alternativa. Esto plantea la pregunta: ¿Puede Dios conocer las acciones futuras y libres de los hombres? He tratado de justificar una respuesta negativa a esta pregunta, basándome en una teoría que atribuyo a Von Wright. Pero resulta que Von Wright no reconoce la paternidad de la doctrina que le adjudico. En una carta fechada en febrero de 1977 dice expresamente: "Temo que mis pensamientos mal expresados y parcialmente incorrectos han llevado a malos entendidos. Así, por ejemplo, no he querido decir que las proposiciones contingentes acerca del futuro carecen de valor de verdad - lo que significaría que es lógicamente imposible conocerlas. La proposición 'mañana lloverá' es verdadera o falsa (cuando se ha fijado el 'hoy'). Y esto quiere decir tan sólo que (es lógicamente verdadero que) mañana lloverá o no lloverá. De ahí no se sigue, sin embargo, que el valor de verdad está determinado ya ahora, que es seguro si va a llover mañana o no. (La seguridad de la que se trata aquí no es algo meramente 'psicológico'. 'Es seguro' no significa lo mismo que 'Estoy seguro [convencido, tengo una fe firme]'.) Se sigue de lo dicho que no puedo estar de acuerdo con el punto de vista de que el problema de si las proposiciones acerca de los eventos futuros contingentes pueden ser verdaderas se reduce a la cuestión de si el futuro es lineal o ramificado."

4. De modo que la teoría sostenida en mi artículo debe considerarse mía, y su atribución a Von Wright, fruto de una ilusión óptica. No obstante esa capitis diminutio sigo 
creyendo que la teoría contiene algo de verdad. En especial, creo que el hecho de que las proposiciones futuras contingentes tengan valor de verdad implica la linealidad del futuro y que la linealidad del futuro implica determinismo. Pero hay que distinguir - cosa que no hago en el artículo y sí hace Von Wrihgt en Causality and Determinism- entre diversas formas de determinismo. La tesis "determinismo = determinismo causal" que parece implícitamente aceptada en el artículo, es ciertamente falsa. Como se encarga de señalar Rodríguez Larreta, la linealidad del futuro no implica determinismo causal. Lineal significa ausencia de alternativas reales (ontológicas) : hay un solo estado total del mundo en cada momento temporal, pero los distintos estados no tienen por qué estar conectados entre sí por leyes causales.

Sin embargo, si por "determinismo" entendemos que los eventos futuros no admiten alternativas reales (que el futuro no es ramificado, sino lineal, como el pasado), entonces resulta -ex definitione- que si el futuro es lineai, está determinado. En Causality and Determinism (pp. 11-115) Von Wright habla del "step-by-determinism", ejemplificándolo precisamente en el determinismo a través del conocimiento anticipado de Dios. Si Dios conoce todos los hechos futuros, tales hechos no son contingentes, sino en cierto sentido necesarios (a saber, en el mismo sentido en que los escolásticos decían que son necesarios los hechos pasados). Y me parece que tal conocimiento sería incompatible con la libertad: en este caso sería verdadero el segundo cuerno del dilema de Orayen, pues no habría futuros contingentes. Q.E.D. 